\title{
A risk assessment of the food supply chain: vulnerability against terrorist or criminal contamination
}

\author{
M.J. Alvarez* and A. Alvarez \\ Tecnun (Universidad de Navarra), \\ Paseo Manuel Lardizabal 13, 20019 San Sebastián, Spain \\ E-mail: mjalvarez@tecnun.es \\ E-mail: aalvarez@tecnun.es \\ *Corresponding author
}

\section{De Giacomo}

Istituto Superiore di Sanità,

Viale Regina Elena 299, 00161, Rome, Italy

E-mail: marzia.degiacomo@iss.it

\section{M.C. De Maggio}

Università Campus Bio-Medico di Roma, Via À. del Portillo, 21, 00128, Rome, Italy

E-mail: M.DeMaggio@unicampus.it

\section{R. Onori}

Istituto Superiore di Sanità,

Viale Regina Elena 299, 00161, Rome, Italy

E-mail: Roberta.onori@iss.it

\section{A. Oses and J.M. Sarriegi}

Tecnun (Universidad de Navarra),

Paseo Manuel Lardizabal 13, 20019 San Sebastián, Spain

E-mail: aoses@tecnun.es

E-mail: jmsarriegi@tecnun.es

\section{R. Setola and M. Trombetta}

Università Campus Bio-Medico di Roma, Via À. del Portillo, 21, 00128, Rome, Italy E-mail: r.setola@unicampus.it

E-mail: m.trombetta@unicampus.it 
Abstract: The food supply chain has been recognised by the USA and the EU as a critical infrastructure, and it should be considered a target for possible terrorist attacks. In this paper, we present a methodological approach developed within the EU project SecuFood to evaluate the risk associated with this threat. The usefulness of the approach is related to the improvement of the analysis of food supply chain risk in terms of the potential threats, the vulnerability of the system, and the effectiveness of counter measures.

The followed approach is based on identifying biological and chemical hazards, analysing those biological and chemical agents, and determining the risk level they present in the main phases of the food supply chain.

We consider the feasibility of an attack (what we call likelihood), taking into account the accessibility and manageability of the contamination agents, the vulnerability of the supply chain for specific products, and the possible adverse consequences.

Keywords: risk assessment; food supply chain; food defence; food terrorism; USA.

Reference to this paper should be made as follows: Alvarez, M.J., Alvarez, A., De Giacomo, M., De Maggio, M.C., Onori, R., Oses, A., Sarriegi, J.M., Setola, R. and Trombetta, M. (2011) 'A risk assessment of the food supply chain: vulnerability against terrorist or criminal contamination', Int. J. Food Safety, Nutrition and Public Health, Vol. 4, No. 1, pp.63-82.

Biographical notes: M.J. Alvarez holds a $\mathrm{PhD}$ in Agricultural Engineering from the Universidad Politécnica de Madrid (UMP). She is a Professor of Operational Research at the Management Industrial Engineering Department, TECNUN (Universidad de Navarra). Her research activities are in operations research applied to logistics and to the improvement of the productivity of the systems. She has been involved in research projects in these areas. Her results have been published in journals such as Transportation Research, Journal of Quality Technology, European Journal of Operational Research, among others.

A. Alvarez is a graduate of Business Administration (Universidad de Deusto, Spain). She holds a Master degree in Marketing. She has been working in projects related to innovation, marketing and risk assessment.

M. De Giacomo holds a degree in Chemistry and a post-graduate specialisation course in Biotechnology (University of Rome 'La Sapienza'). Her research activities include identification of emerging risks in the field of food production, standardisation of analytical methods for the detection of GMO food, validation of analytical methods by PCR Real Time on final products, comparison of methods of DNA extraction from food, GMO analysis by array and biochips, development of testing and sampling approaches.

M.C. De Maggio is a Researcher at the Complex Systems and Security Laboratory, University Campus Bio-Medico of Rome, Italy. Her research interest include critical infrastructure protection, risks analysis and risks management.

R. Onori holds a degree in Biology from 'Sapienza' University of Rome and a post graduate Master of Science in Statistic and Health Management. Her research interests include the identification of emerging risk in the field of food production and the implementation of traceability system in food and feed chains, particularly on genetically modified organism (GMO) issues. She takes part in national official bodies involved in food safety assessment and to EFSA activities for GMO risk assessment. 
A. Oses is an Engineer of industrial organisation (Universidad del País Vasco, Spain). Her research interests include manufacturing process, supply chain management and risk analysis.

J.M. Sarriegi is an Industrial Engineer and a Professor of Information Systems and Modelling and Simulation at TECNUN. His research interests include security management, knowledge management and complex systems modelling. He has led several research projects in all these topics. $\mathrm{He}$ is currently coordinating with the SEMPOC project. He has published in journals such as IEEE Software, International Journal of Computer Integrated Manufacturing, IEEE Internet Computing and International Journal of Industrial Ergonomics as well as in conference proceedings such as in the Lecture Notes in Computer Science. He has also presented dozens of papers in international conferences.

R. Setola is the Director of the Complex Systems and Security Laboratory, University Campus Bio-Medico of Rome, Italy. His research interests include critical infrastructure modelling and analysis, critical infrastructure protection, risk assessment and control strategies for complex systems.

M. Trombetta is a Professor of Chemical Fundamentals Technology, University Campus Bio-Medico of Rome, Italy. Her research interests include the synthesis and characterisation of new materials for biomedical applications, energy and the environment.

\section{Introduction}

Over the last few decades people have lost confidence in the food production industry (including farms) due to the increasing number of food safety alerts. BSE, dioxins, Salmonella and foot and mouth disease are recent examples. The European Commission reacted to these problems and in 2000 adopted the "White Paper on Food Safety" (EU, 2000a), which established the strategy for a coordinated food safety policy in order to assure high standards of food safety and quality and the highest possible protection of human health. European countries were required to adopt traceability and the hazard analysis critical control point (HACCP) system in 2002 (EC 178/2002; EC 852/2005). Moreover, the European Food Safety Authority (EFSA), an independent agency devoted to improving the quality of risk assessment for food safety and responding to matters raised by European and Member States Authorities and/or at its own initiative was established.

In addition, after September 2001, Western countries discovered in a dramatic way how truly exposed they are to terrorist attacks, forcing them to focus their attention on terrorism and malicious threats in terms of attacks to the food supply chain. The anthrax attacks in 2001 and the ricin attacks in 2003 have also caused concern about the use of biological weapons by terrorist organisations.

Hence, the deliberate contamination of food as a way of attacking the population is increasingly considered a real danger. As a consequence, the food supply chain should be considered a possible target for terrorist or criminal attacks aiming to create a lack of trust and spread panic in developed countries. Many countries are developing "food 
defence strategies" and have classified the food supply chain as critical national infrastructure. This was demonstrated in Aon's (2009) political and economic risk map. A number of well-known examples of such aggressions have been documented in the literature. In 1984, for example, a cult group sprayed Salmonella on salads in ten different restaurants in Oregon, causing 750 people to become ill. In 1996, a hospital employee used the bacterium Shigella dysenteriae to make his co-workers ill. More recently, in 2003 a supermarket employee put insecticide in 200 pounds of ground beef, causing illness in roughly 100 people (Zsidisin and Ritchie 2008). For a more exhaustive survey of food attacks, see Dalziel (2009).

The globalisation of markets increases risks to human health. Authors like Manning and Baines (2004) and Sanders (1999) agree that the globalisation of food production increases the risk of food-borne disease pandemics. For the same reason, deliberate contamination carried out in one country could put consumers in many other countries at risk. This phenomenon is further increased by the mass-scale, illegal importation of food which is not subject to any type of control.

Moreover, due to the multi-disciplinary nature of the topic, several organisations (e.g., law enforcement, food safety agencies, health organisations, food companies, etc.) are in charge of different strategies and potential solutions. This is particularly true at the EU level, where different approaches are in place in each one of the member states (MS), limiting the problem-sharing capability.

According to internationally accepted principles and definitions (FAO/WHO, 1995, 1997; EU, 2000b), risk analysis is the process of making a decision about risks to food safety. Risk is defined as the likelihood that, under particular conditions of exposure, an inherent hazard will signify a threat to human health. Thus, risk is a function of hazard and exposure, where hazard is defined as the likelihood that an agent or situation will cause an adverse health effect/event. Risk assessment is a process of evaluating the likelihood and severity of an adverse effect/event occurring to people or to the environment as a consequence of exposure, under defined conditions, to a risk source. A risk assessment includes: hazard identification, hazard characterisation, exposure assessment and risk characterisation. Risk management is the process of weighing policy options according to a risk assessment and of making other significant evaluations, and if necessary, of selecting and implementing appropriate control options (including monitoring and surveillance activities). Risk communication is the interactive exchange of information about and opinions on risk throughout the risk analysis process.

Recently EFSA (2010) published a Technical Report on the development and implementation of a system for the early identification of emerging risks to food and feed. In this report, several drivers of change were reported to have a probable impact on food safety in the mid- or long-term (Havelaar et al., 2009; Kleter and Marvin, 2009; Quested et al., 2010): climate change; the genetic evolution of pathogens; the intensification of livestock husbandry, including aquaculture; environmental contamination from persistent chemicals for which little toxicological information exists; the recycling of food and animal processing waste into animal feed; changes and innovations in food processing; changes in consumer behaviour and preferences; lack of legislation; globalisation; international trade; demographic changes; and fluctuations in food prices (Havelaar et al., 2009; Kleter and Marvin, 2009). The report establishes a data monitoring capacity, data filtering methodology and networking structures to identify emerging risks in a timely manner and to communicate 
them to risk managers. Three principle sources of information, the rapid alert system on food and feed (RASFF), the media, and trade data, have been identified and assessed. In addition, the scientific literature is monitored. Further, data sources will be added to the regular monitoring. In particular, networking with stakeholders, MS, EU and international agencies is seen as a key step in developing effectiveness in this process. However, no mention of criminal attacks to the food chain as an emerging risk is reported.

In this paper, we illustrate the methodological approach developed within the research project "Security of European Food Supply Chain" (SECUFOOD http://www.secufood.unicampus.it), co-funded by the European Commission under the Programme "Prevention, preparedness and consequence management of terrorism and other security-related risks". Our approach is designed to detect the vulnerabilities of the food supply chain and to assess the risk of a terrorist attack. Specifically, Section 2 gives an overview of the proposed risk assessment models, their benefits and limitations, and illustrates the chosen methodology. In Section 3, we show the results of the application of the methodology to a set of food products and, finally, in Section 4, we draw some conclusions.

\section{Methodology}

The food sector is vulnerable to both voluntary manipulation and involuntary incidents that could cause social alarm or even disease in the population (World Health Organization - Department of Food Safety, 2008). In addition to these 'traditional' threats, we also have to consider criminal and terrorist attacks so as extreme events (e.g., natural disasters or cascading failures). Moreover, contamination/manipulation may happen at any point in the chain that goes from the farm to the fork. The location of such adulteration and the nature of the contaminating agents greatly influence the magnitude of the hazard in terms of effectiveness and casualties (Boddie and Kun, 2008). This stresses the need to perform a risk analysis that is able to highlight the most critical elements, allowing prevention strategies, adequate countermeasures and appropriate incident handling methodologies (including early warning and rapid alert systems) to be efficiently defined.

To carry out such an analysis, we decompose a general food supply chain into its macro steps. Indeed, a food supply chain typically starts from farms and involves many different types of facilities (including processors, packers, distributors, drivers, and retail stores) before finally reaching the consumer. Figure 1 shows a generic food supply chain.

We considered the risks associated with such a supply chain using dedicated sets of criteria for each one of the macro steps of the food supply chain, in order to capture the peculiar characteristics of the different steps. In fact, there are significant differences among each macro step in terms of time, complexity, destination, etc. All of these features influence attacker accessibility, step vulnerability and potential impact consequences (Setola and De Maggio, 2009). For that reason, we carried out an individual assessment for each of the main macro steps, excluding the farm and the points of sale. 
Figure 1 General food supply chain

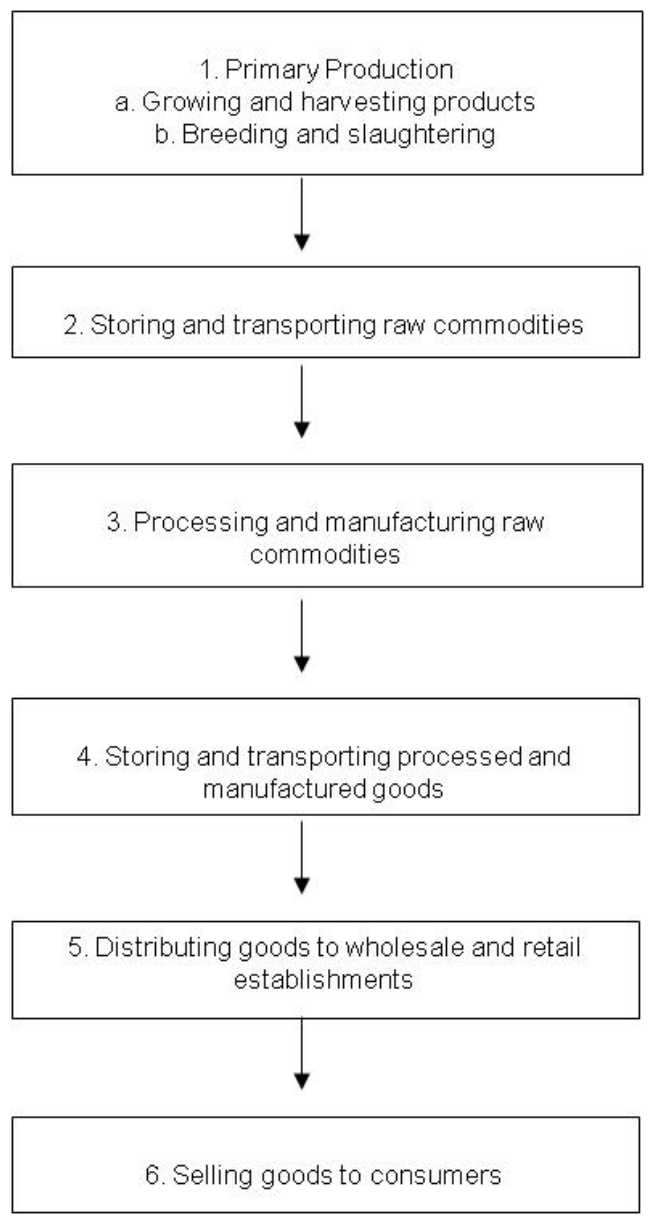

\subsection{Risk assessment}

Risk has been broadly defined as the chance of damage, loss, injury, danger or any other undesired consequence occurring. However, Warner (1986) gives a more scientific definition: "The probability that a particular adverse event occurs during a stated period of time, or results from a particular challenge [...]". Zsidisin and Ritchie (2008) defined supply chain risk as "the potential occurrence of an incident or failure to seize opportunities with inbound supply in which its outcomes result in mainly financial loss for the [purchasing] firm".

In terms of the topic of this paper, we should complement the definition of risk by adding the following definition of food terrorism, given by the WHO (2008): "an act or threat of deliberate contamination of food for human consumption with biological, chemical and physical agents or radio nuclear materials for the purpose of causing injury or death to civilian populations and/or disrupting social, economic or political stability".

As Ezell and Winterfieldt (2009) pointed out, the probabilities of an attack are hard to assess, requiring knowledge about motivations, intent and terrorist capabilities. In 
addition, these probabilities change as defence actions change. Therefore, we focused our attention on detecting vulnerabilities in the food chain, making it possible to take preventative measures. Our approach is mainly qualitative. Other authors recommended a similar approach to this issue; Svensson (2004) suggested a qualitative measure to gauge corporate perceptions of supply chain vulnerabilities.

What we address here is a risk assessment of the food supply chain with the purpose of identifying vulnerabilities in the food supply chain with respect to malicious actions performed by outsider or discontented insider enemies. Other components of risk analysis, such as risk communication, risk management, and decisions about safety measures or their implementation, are beyond the scope of our research.

According to the conventional approach to risk analysis (EU, 2000b), the very first step in risk analysis is hazard identification. A threat assessment is usually conducted to discover the likelihood of occurrence for each threat. Concerning food safety, likelihood can be estimated using a historical database of the frequency of similar incidents. However, such an approach cannot be adapted to estimate the probability of a terrorist attack due to the fortunate scarcity of such events and because terrorist attacks cannot be quantified statistically due to the arbitrary nature of terrorism definition.

To overcome such difficulties, we focus on the 'attractiveness' of any single facility as a possible target for a terrorist attack. Obviously, the easier it is to access a facility, the more likely the attack will be performed there, and vice versa. Here, we refer both to accessibility to the target and the accessibility of the contaminating agent. However, one has to also consider the potential consequences of such an attack in terms of causalities, public effects, panic, etc.

Hazard characterisation, exposure assessment and risk characterisation are steps in which the probability of occurrence for each attack is identified and the consequences of the impact of each one are estimated. We carried out these steps using a Risk Assessment Matrix, making adjustments to the calculation of likelihood.

\subsection{Likelihood matrix}

In our framework, by the term 'Likelihood' we refer to the probability that an attack will occur and we consider two variables that affect likelihood: the probability of access to the contaminant and the vulnerability of the food supply chain. Both probability of access and vulnerability depend on the step in the supply chain being considered. The proposed methodology looks at three main steps, the manufacturing phase (A), transportation phase (B), and warehouse phase (C). Our approach is based on an analysis of the food chain and on the results of the interviews with companies involved in the food sector.

Probability of access is the probability that a terrorist (or more generally, an enemy) could access the substance, powder, etc., that could cause damage. If the agent is easy to access, the probability of it being used for an attack is higher. Probability of access is measured by the facility of producing the agent (Bokan, 2001).

Vulnerability, for our purposes, is considered to be a measurement of how much a given facility is susceptible to attack. This is going to be an important variable in determining which target is chosen by the terrorists. If the vulnerability of a specific point in the supply chain is high, it is more likely that this specific point will be chosen by terrorists (Jackson and Frelinger, 2009).

Vulnerability to chemical agents was estimated taking into account the characteristics of the possible agent. Thus, if an agent is the same colour as the food (white in the case of 
milk, for instance), vulnerability will be higher. Similarly, if the chemical agent is colourless and odourless, the vulnerability of the food supply chain step will be higher than if an agent that has a colour and/or an odour. In the case of biological agents, the existences of high temperature treatments or microbiological testing are more important from the point of view of vulnerability. In the same way if the access to the food is difficult, i.e., due to the packaging characteristics or because it is confined inside hermetic pipelines, than it is less vulnerable with regards to situations when the enemy can be easily in direct contact with the food.

\section{A Manufacturing phase}

Based on the interviews carried out with experts and food company operators, we take into account the following characteristics of the process:

- type of process (whether the product is visible or not, whether the product is directly accessible or not, whether the process has specific peculiarities, etc.)

- company policies regarding employees, such as employee control, employee access (total vs. restricted - i.e., only for the workers operating there), cleaning procedures, etc.

- company policies regarding visits (escorting, access control, registration, possibility of being alone, etc.)

- security (alarms, cameras, guards, etc.)

- quality control procedures: this factor provides information regarding the capability of the company to detect contaminating agents.

\section{B Transportation phase}

The study of transportation is divided into two phases: the transport of raw materials (the raw material delivered to the company) and the transport of the manufactured products (finished goods transport). The main difference between these two sectors is how the goods are transported. For example, raw milk is liquid and needs a special truck while the output is in bottles or other kinds of packaging and so it could be transported with other products in a refrigerated van.

Furthermore, according to the transportation companies we interviewed, access to their trucks is very difficult as they are sealed throughout the entire route. However, they also admitted that once they reached their destination, depending on the route, they often found illegal immigrants hidden inside the truck with no visible signs of forced entry. Consequently, we can conclude that it is not overly difficult to open or change the seals.

For the transportation phase, based on the interviews carried out, the methodology of this study considers vulnerability according to the following factors:

- Type of product (form): Liquids were set as likely since the contaminating agent would spread rapidly, while solids were set as unlikely.

- Package: Glass and Tetra Brik were set as unlikely, plastic cups or bottles were considered possible and open-air products (such as bread and bakery products) or other examples of vulnerable packaging were set as likely. 
- Type of transportation needed (truck, refrigerated truck, liquid truck, ship) and accessibility: Simple trucks were set as likely due to their high accessibility; refrigerated trucks were set as possible; liquid trucks were set as unlikely; and ships were set as rare.

\section{Warehouse phase}

Our study of the warehouse does not differentiate the wholesaler's storeroom from the retailer's storage except in terms of one aspect: storage temperature. Two analyses were carried out, one for products that require refrigeration and another for those that do not require it.

For the warehouse phase, just as in the manufacturing and in the transportation phases, we based our methodology on the interviews carried out with experts from companies and considered vulnerability according to the following factors:

- Type of product (Package): Glass and Tetra Brik were set as unlikely, plastic cups or bottles were set as possible and open-air products (such as bread and bakery products) or vulnerable packaging were set as likely.

- Accessibility (security, policies regarding employees, policies regarding visits). This is assessed in the same way as in the manufacturing phase.

- Type of warehouse (refrigerated and non-refrigerated). Refrigerated warehouses were considered to be unlikely, whereas non-refrigerated ones were set as likely.

After defining the vulnerability and probability indexes, we used the likelihood matrix to estimate likelihood. In this matrix, the rows represent degrees of vulnerability for each step of the supply chain, and the columns represent probabilities of access to the agent. The hazardous components which could be used by an attacker are placed in a cell of the likelihood matrix based on the probability of access to that component and the vulnerability of the step in the supply chain. The result represents the probability of an attack with that element at that step (Figure 2). Probability of access, vulnerability and likelihood are classified into the following five categories: rare (R), unlikely (U), possible (P), likely (L) and almost certain (AC).

Figure 2 Likelihood analysis matrix

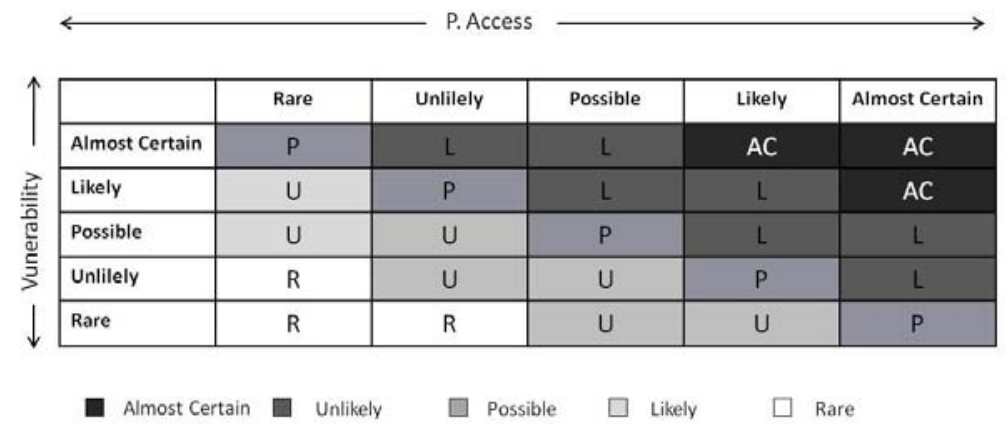

Note: Likelihood $=\mathrm{P}($ Access $) *$ Vulnerability 
Once the probability of an attack is known and its hazard component analysed, it is easier to locate it on the horizontal axis of the principal matrix (the risk assessment matrix).

\subsection{Risk assessment matrix}

In order to be able to estimate the level of risk, we used a risk assessment matrix, which is similar to the one used in operational risk management (ORM). In our matrix, rows represent the likelihood estimated by the likelihood matrix as shown above, and columns represent the effect(s) of the agent. The intersection of the likelihood row and the consequence column defines the level of risk. We used the following five levels of risk: tolerable $(\mathrm{T})$, low $(\mathrm{L})$, moderate $(\mathrm{M})$, high $(\mathrm{H})$ and extreme $(\mathrm{E})$, as can be seen in Figure 3.

\subsubsection{Consequences}

The consequence is the result of the attack, and it is related to the severity of the effect of the contaminant agent. We took into account mainly physical and psychological health consequences. The degree of severity of the consequences was classified into five categories: insignificant, minor, moderate, major and catastrophic. We followed a slightly different approach in studying the consequences of biological agents and chemical agents and toxins.

\subsubsection{Consequences of biological agents}

- Effects: The effects that the attack can cause, measured in terms of both physical and psychological consequences.

- Persons affected: the number of people affected physically and/or psychologically.

Consequences were measured on a scale of 1 to 5 , with 1 being insignificant while 5 is catastrophic. The following is an explanation of the classification system used in this study.

- Catastrophic: A large number of deaths, large-scale panic in the population, significant impact on national economy.

- Major: Some deaths, severe injuries, anxiety in the population, considerable economic losses for food operators (bankruptcy).

- Moderate: Some people require medical attention, considerable mass-media attention and economic losses for food operators.

- Minor: No relevant illness, some mass-media coverage, marginal economic losses.

- Insignificant: Irrelevant injuries sustained, news limited to specialised press, no significant economic losses.

\subsubsection{Consequences of chemical agents and toxins}

For these kinds of agents we considered the severity of the consequences in terms of lethal doses. The smaller the dose, the more severe the consequence of the chemical agent 
is. In other words, the agent could be considered more dangerous. We have incorporated the toxicity classification proposed by Gosselin et al. (1984).

Table 1 Toxic rating

\begin{tabular}{lcc}
\hline & Toxicity classes: Gosselin, Smith and Hodge \\
\hline \multicolumn{1}{c}{ Poxicity rating } & Dose & For $70 \mathrm{~kg}$ person (150 lbs) \\
\hline Super toxic & Less than $5 \mathrm{mg} / \mathrm{kg}$ & 1 grain (a taste - less than 7 drops) \\
Extremely toxic & $5-50 \mathrm{mg} / \mathrm{kg}$ & $4 \mathrm{ml}$ (between 7 drops and 1 tsp) \\
Very toxic & $50-500 \mathrm{mg} / \mathrm{kg}$ & $30 \mathrm{ml}$ (between 1 tsp and $1 \mathrm{fl}$ ounce) \\
Moderately toxic & $0,5-5 \mathrm{~g} / \mathrm{kg}$ & $30-600 \mathrm{ml}$ (between $1 \mathrm{fl}$ oz and 1 pint) \\
Slightly toxic & $5-15 \mathrm{~g} / \mathrm{kg}$ & $600-1,200 \mathrm{ml}$ (between 1 pint to 1 quart) \\
Practically non-toxic & Above $15 \mathrm{~g} / \mathrm{kg}$ & more than $1,200 \mathrm{ml}$ (more than 1 quart) \\
\hline
\end{tabular}

The consequences were measured on the same 1-5 scale. In this study, we associated Gosselin's toxicity rating to each consequence:

- catastrophic: super toxic

- major: extremely toxic

- $\quad$ moderate: very toxic

- minor: moderately toxic

- insignificant: slightly toxic and practically non-toxic.

Once the likelihood and the consequences are estimated for a specific agent in a particular step of the supply chain, we can use the risk assessment matrix to obtain the level of risk.

Figure 3 Risk assessment matrix

\begin{tabular}{|c|c|c|c|c|c|}
\hline \multirow[b]{2}{*}{ Almost Certain } & Insignificant & Minor & Moderate & Mayor & Catastrophic \\
\hline & $M$ & $H$ & $H$ & E & $E$ \\
\hline Likely & L & M & H & $H$ & E \\
\hline Possible & L & L & M & H & H \\
\hline Unlilely & T & L & L & M & $\mathrm{H}$ \\
\hline Rare & T & $T$ & L & L & L \\
\hline
\end{tabular}

Source: FDA, US Food and Drug Administration (2009) 
74 M.J. Alvarez et al.

Table 2 Food selection

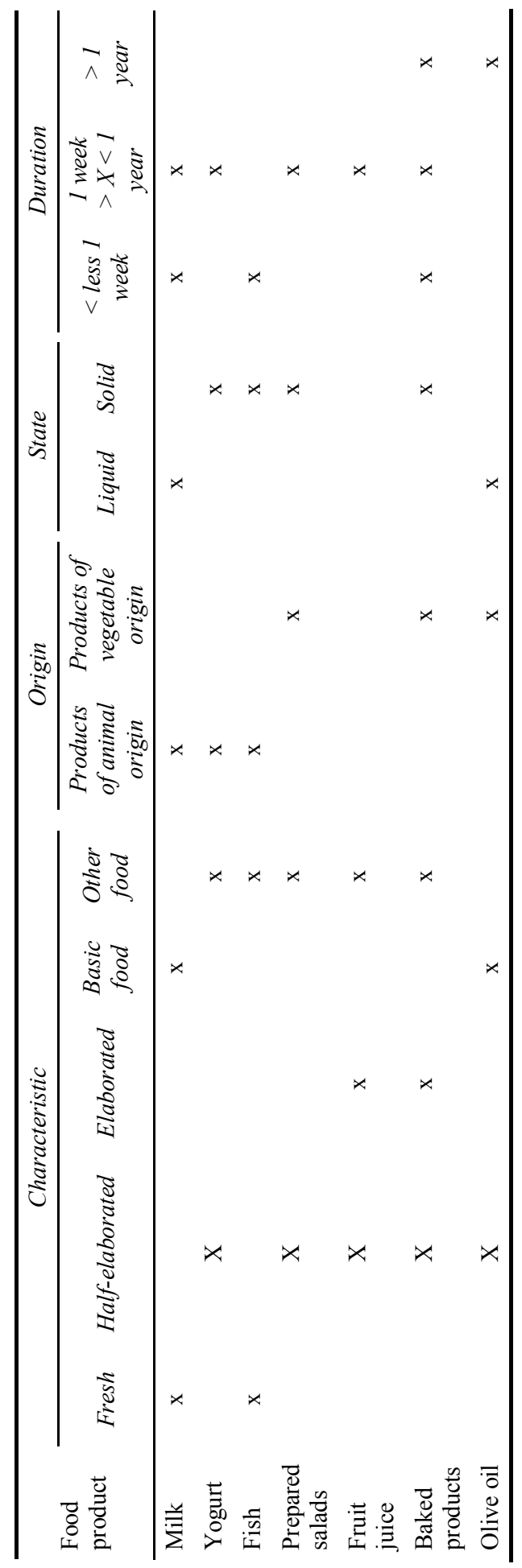




\section{Results and discussion}

\subsection{Application of the methodology}

There is great heterogeneity among the different types of food. Therefore, each type of food needs a specific approach. For that reason, a feasible approach is to select a set of food types to represent specific food sectors in order to study them in depth. Within the SecuFood project, to ensure ample representation, we included the following types of food:

- fresh and processed food products

- food of animal or plant origin

- liquid and solid foods

- food of varying shelf life

- basic and non-basic foods.

We use basic food as a synonym for staple food; that is, food that is regularly consumed in a community or society and from which people obtain most or a significant proportion of their calorie requirements. Bread and pasta are examples of basic food in Western countries.

As a result, we chose different representative food products and analysed the food supply chain for each one. The types of food selected were milk, yoghurt, fresh fish, processed fish, prepared salad, fruit juice, olive oil, bread and bakery products. The selection of food products presented in Table 2 includes all the types of food mentioned above.

We applied the methodology to each macro-step of the supply chain for these food types. For each step of each food item we built two likelihood matrices and two Risk Assessment Matrices, one for biological agents and one for chemical agents, considering totally about 30 different contaminant agents (for a complete list and more details see SecuFood deliverable available at http://www.secufood.unicampus.it/).

In this paper, we describe the implementation of our methodological approach through a case study dealing with the manufacturing step for yoghurt.

\subsection{Hazard identification}

Thanks to several studies on agents that can contaminate food or water (IFIC, 2006; Khan et al., 2001; Shea and Gottron, 2004; Rasco and Bledsoe, 2005) and several extensive interviews we conducted with experts during the project, it was possible to construct a list of the main biological and chemical agents that can be used to intentionally contaminate food (Tables 3 and 4).

Although the probability of an attack could not be estimated using historical data, we did an historical review and we selected some of the agents that have been used in malicious food contamination or that have a high potential to be used. We did not consider every possible chemical agent and every possible biological agent, and other agents could very well be used. However, we intend to demonstrate the vulnerabilities of the food sector with the chosen set of agents. 
Table 3 Biological agents that could be used to intentionally contaminate milk

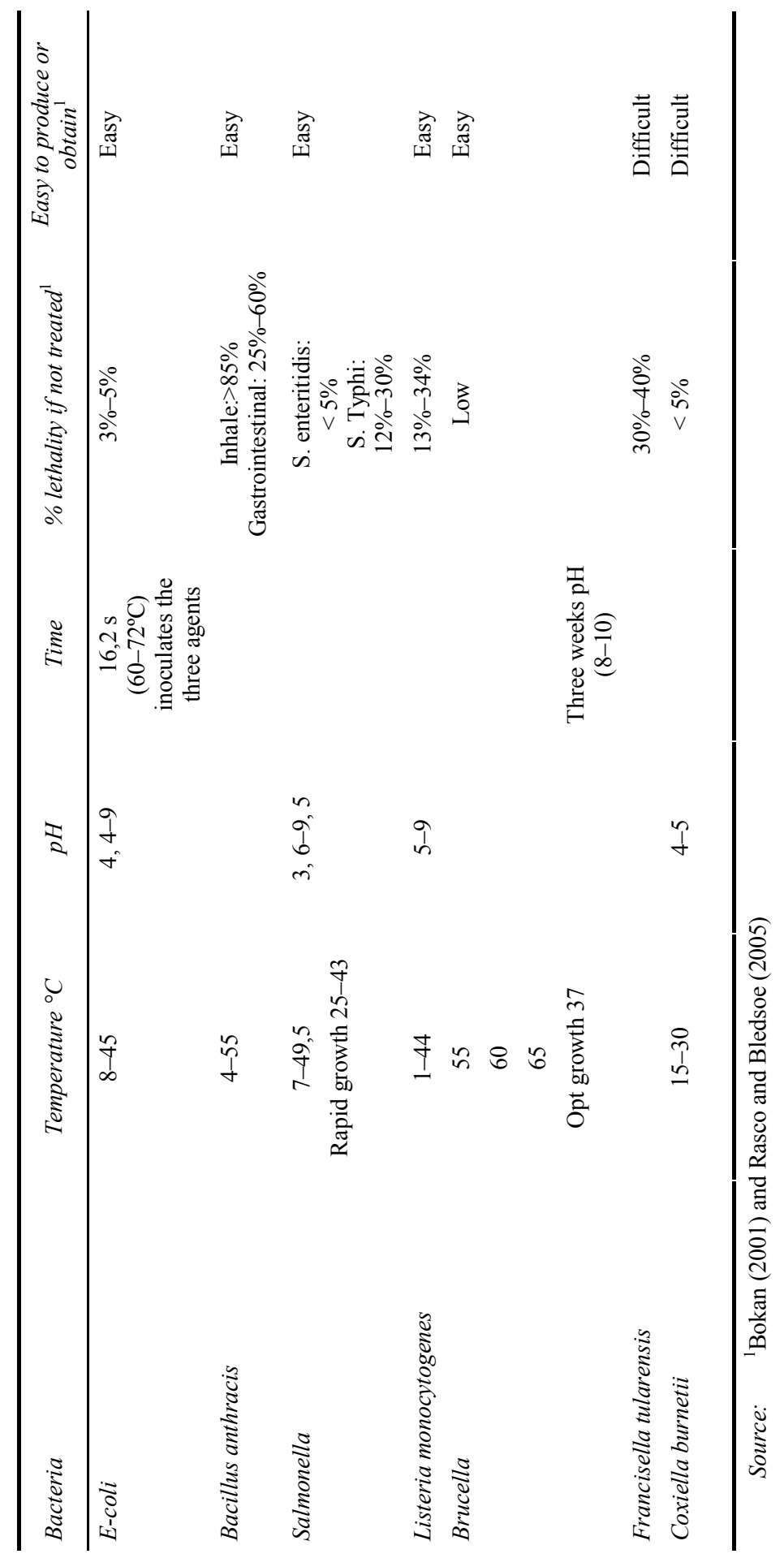


Table 4 Chemical agents that could be used to intentionally contaminate milk

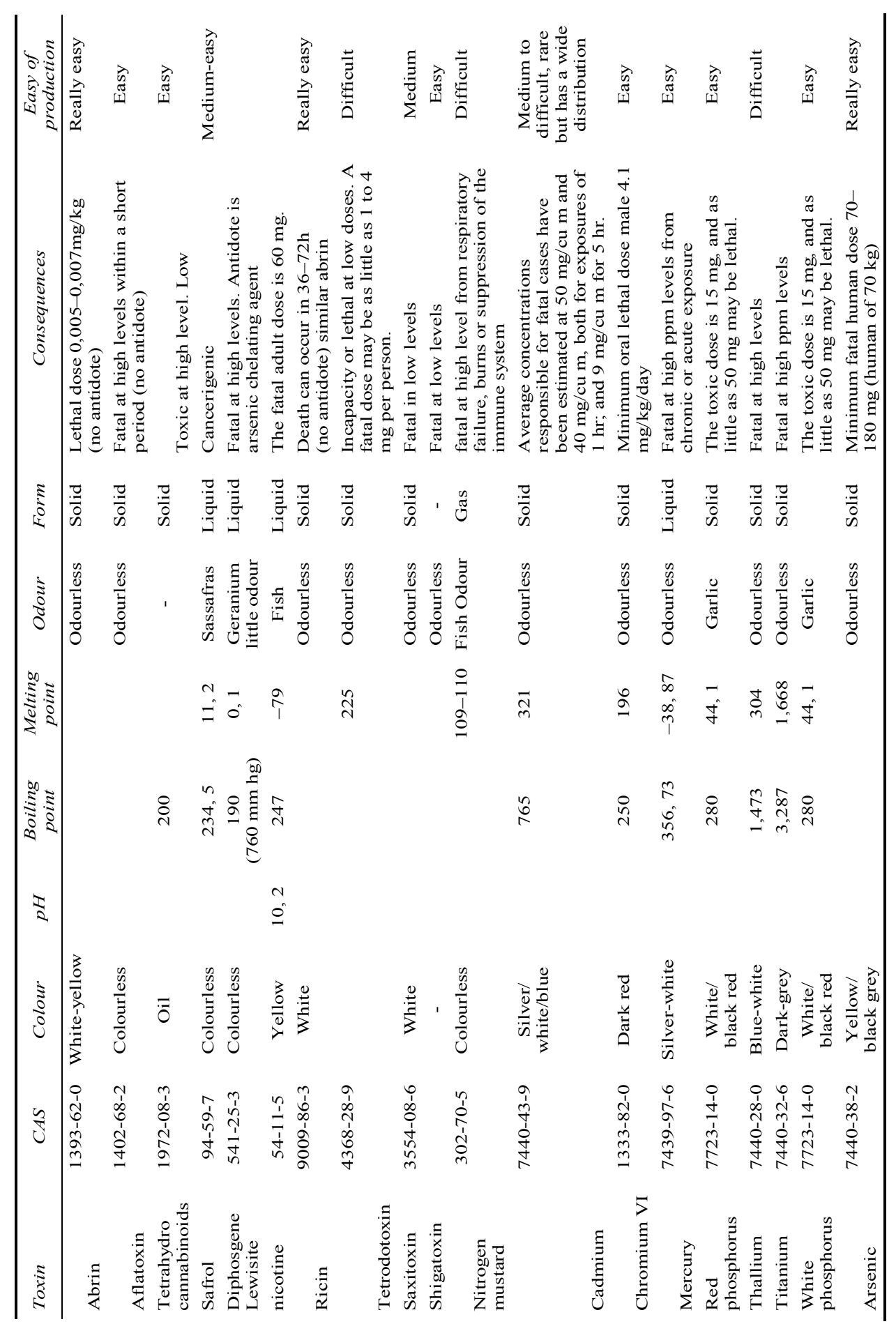




\subsection{Study case: the manufacturing step for yoghurt}

As a case study to illustrate our methodology, we focused on the risk assessment of the manufacturing phase for yoghurt with respect to biological and chemical agents. For details about the entire yoghurt supply chain and other types of foods analysed (i.e., milk, fresh fish, processed fish, prepared salad, fruit juice, olive oil and bread and bakery products) that cannot be reported here due to limited space, please refer to SecuFood deliverables (SecuFood - http://www.secufood.unicampus.it).

Figure 4 Likelihood analysis for the yoghurt sector

Probability of access

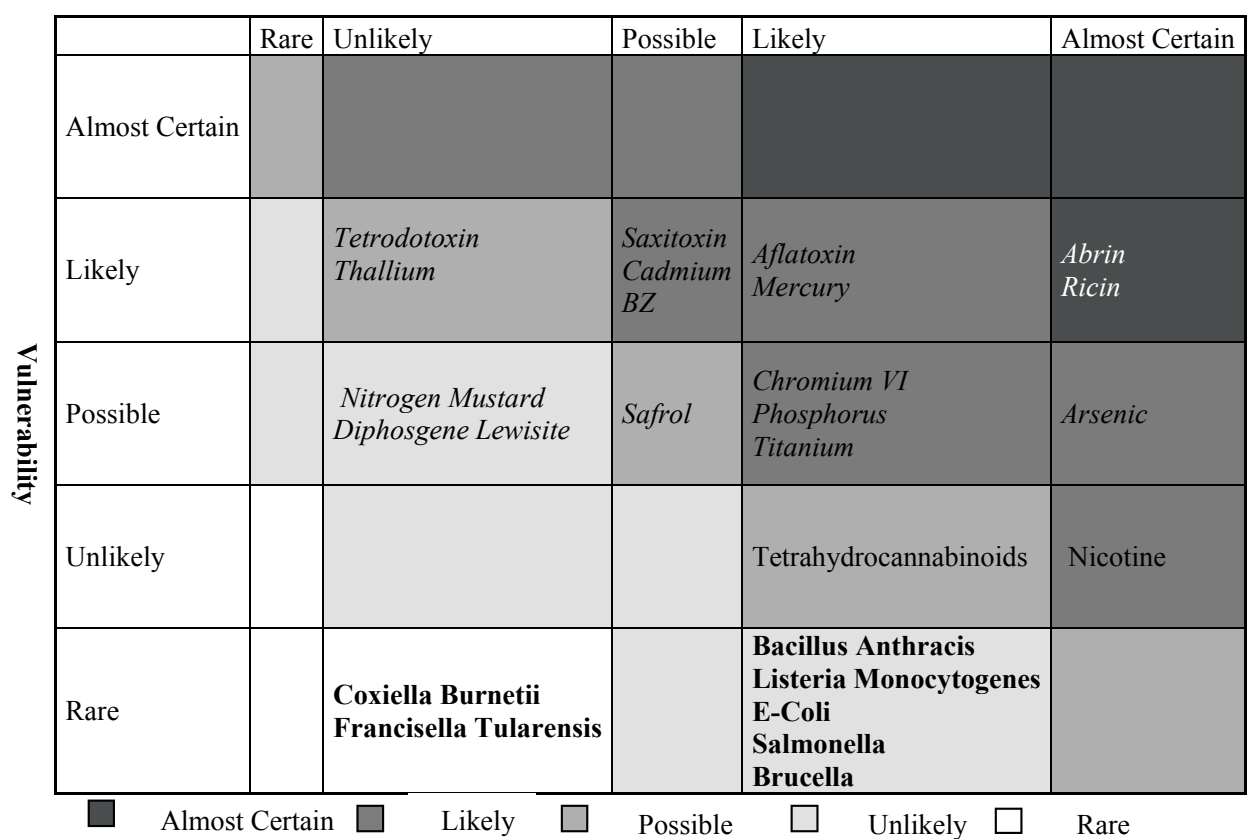

Note: Biological agents are in bold and chemical agents are in italics.

According to the list of the main biological and chemical agents that can be used to intentionally contaminate food (Tables 3 and 4), access to the following biological agents was deemed likely: Bacillus anthracis, Listeria monocytogenes, E-Coli, Salmonella and Brucella. Access to Coxiella burnetii and Francisella tularensis were determined to be unlikely. For chemical agents and toxins, the probabilities of access were as follows: $A C$ (Abrin, Ricin, Arsenic, Nicotine), L (Phosphorus, Aflatoxin, Shigatoxin, Chromium VI, Mercury, Tetrahydrocannabinoids, Titanium), $P$ (Saxitoxin, Cadmium, Safrol, BZ) and $U$ (Tetrodotoxin, Thallium, Nitrogen Mustard, Diphosgene Lewisite).

Vulnerability is considered to be rare for biological agents, while for chemical agents and toxins it changes according to the characteristics of the agent. For instance, the process is less vulnerable to Nicotine than to Aflatoxin due to the fact that Nicotine has a characteristic odour and yellow colour while Aflatoxin is odourless and colourless, rendering it more difficult to detect in the absence of chemical controls. 
It can be seen that the vulnerability is greater for chemical agents and toxins. The main reason is that during the yoghurt manufacturing process, several microbiological controls are performed whereas there is almost no control for chemical contaminants.

As described in the methodology section, having estimated the likelihood and the consequences of the agents, the level of risk of an attack with each agent in this phase of the production process can be determined.

Figure 5 Risk assessment matrix for yoghurt sector

Consequences

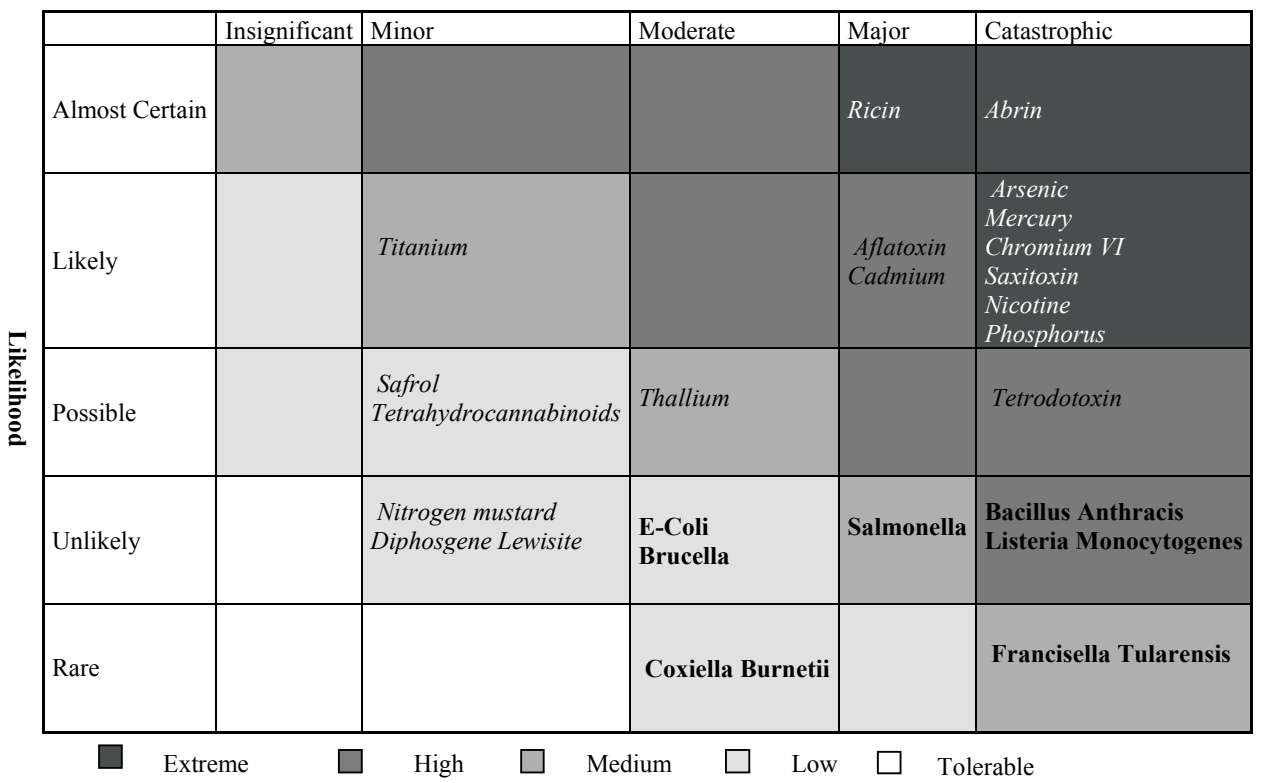

Note: Biological agents are in bold and chemical agents are in italics.

\section{Concluding remarks}

According to the interviews carried out with experts from food companies and with competent authorities, the food sector is prepared to avoid spontaneous contamination, but it is not fully prepared to prevent malicious contamination. HACCP and traceability guidelines provide fit for purpose controls and measures against the dangers of zoonoses and other health risks of microbiological origin. Nevertheless, the food industry as a whole, even if has slight perception of the risk from deliberate contamination, claims that terrorist attacks could occur anywhere along their production process. Hence, the food sector admits the presence of vulnerabilities in the process.

In this scenario, we developed an approach with the purpose of detecting the vulnerabilities in the food supply chain and assessing the risk of malicious attacks. The novelty of the approach described in this article is the evaluation of likelihood, considering the peculiarities of the food product and of the manufacturing process, and the evaluation of the ease with which the dangerous agents can be produced or obtained. The proposed risk assessment methodology focuses on: 
- the vulnerability of the food supply chain phases

- the attractiveness of any single facility as a possible target for a terrorist attack

- the accessibility of the biological or chemical agent to be acquired as contaminating agent

- the potential consequences of such an attack in terms of causalities, public effects, panic, etc.

Hazard characterisation, exposure assessment and risk characterisation are the steps for which the probability of occurrence (likelihood matrix) for each attack is identified (evaluation of vulnerability and probability of access) and the consequences of each one are estimated (risk assessment matrix).

According to our analysis, the following conclusions can be drawn.

- Depending on the phase in the food supply chain where deliberate contamination occurs, the consequences are different. When the attack takes place closer to the consumer, it has a greater probability of success but affects fewer people. On the other hand, if the attack takes place during the first phases of the supply chain, more people will be affected, although the risk is lower due to the strict controls that companies usually have in place.

- The transportation and storage phases are more vulnerable than the manufacturing phase when the attack is perpetrated with biological agents. There is less vigilance and they take longer in terms of time. In general, final products (protected by packaging) are less vulnerable during transportation than raw materials due to the strict controls that manufacturers put on their inputs. However, the transportation of final products is more dangerous. If terrorists introduce a contaminant in the final product (during transportation or in the warehouse) the probability of it not being detected is very high and the consumer's risk of being contaminated is very worrying. In the case of chemical agents, the risk level is higher during the manufacturing steps than during the others. The reason is that, in general, there is an absence of adequate controls for chemical agents during the manufacturing phase.

- The risk assessment analysis shows higher risk in attacks using chemical agents than when biological agents are used. There is a higher number of extreme-level risks for chemical agents than for biological agents during each step in the food supply chain. The main difference in the probability of success with chemical and biological agents is due to quality controls that detect agents. There are hardly any controls for chemical agents in these companies, which makes these agents really dangerous. On the other side, biological agents are much more controlled, which is why the processes are less vulnerable to biological agents. As a consequence, processes have a higher risk of not detecting a chemical attack in time.

- Although these were not the focus of our analysis, it was apparent that there some basic operations within the food supply chain where precautionary measures should be taken. Water-soluble chemical agents and microbiological agents could be added during the washing operation. Furthermore, mixing and adding additives are operations where adding agents are most effective in terms of spreading the contamination. 


\section{Acknowledgements}

This research has been partially supported by the European Commission, Directorate-General for Justice, Freedom and Security within the Programme "Prevention, preparedness and consequence management of terrorism and other security-related risks" under the grant JLS/2008/CIPS/022 SecuFood - Security of the European Food Supply Chain.

\section{References}

Aon Corporation (2009) 'Political risk map', available at http://www.aon.com/risk-services/ terrorism-risk-map/index.html (accessed on November 2010).

Boddie, W.S. and Kun, L. (2008) 'Health care, public health, and the food and agriculture critical infrastructures', IEEE Engineering in Medicine and Biology Magazine, Vol. 27, No. 6, November/December.

Bokan, S. (2001) 'Possible criteria for selecting human, animal and plant pathogens and toxins for the BTWC', The ASA Newsletter, Issue 83, 18 April, available at http://www.asanltr.com/ newsletter/01-2/articles/BOKAN_criteria.htm (accessed on July 2011).

Dalziel, G.R. (2009) Food Defence Incidents 1950-2008: A Chronology and Analysis of Incidents Involving the Malicious Contamination of the Food Supply Chain, Centre of Excellence for National Security (CENS) of the S. Rajaratnam School of International Studies (RSIS) at Nanyang Technological University, Singapore, available at http://www.rsis.edu.sg/cens/publications/reports/RSIS_Food\%20Defence_170209.pdf (accessed on July 2011).

EC (178/2002) European Commission No 178/2002 of the European Parliament and of the Council of 28 January 2002 laying down the general principles and requirements of food law, establishing the European Food Safety Authority and laying down procedures in matters of food safety.

EC (852/2005) European Commission No 852/2004 of the European Parliament and of the Council of 29 April 2004 on the hygiene of foodstuffs.

European Commission (2000a) 'White Paper on food safety in the European Union', COM, No. 99, p.719, 12 January, available at http://ec.europa.eu/dgs/health_consumer/library/pub/pub06_en.pdf (accessed on July 2011).

European Commission (2000b) 'First report on the harmonisation of risk assessment procedures Part 1: the report of the scientific steering committee's working group on harmonisation of risk assessment procedures in the scientific committees advising the European Commission in the area of human and environmental health', 26-27 October 2000, Scientific Steering Committee, European Commission, Brussels, available at http://www.ec.europa.eu/food/fs/sc/ssc/out83_en.pdf (accessed on July 2011).

European Food Safety Agency Journal (EFSA) (2010) 'Development and implementation of a system for the early identification of emerging risks in food and feed', EFSA Journal, Vol. 8, No. 10, p.1888, available at http://www.efsa.europa.eu/en/efsajournal/scdoc/1888.htm (accessed on July 2011).

Ezell, B.C. and Winterfeldt, D.V. (2009) 'Probabilistic risk analysis and bioterrorism risk', Biosecurity and Bioterrorism: Biodefense Strategy Practice and Science, Vol. 7, No. 1, pp.108-110.

FAO/WHO (1995) 'Application of risk analysis to food standards issues', Report of the Joint FAO/WHO Expert Consultation, Geneva, Switzerland, 13-17 March, Food and Agriculture Organisation, Rome, available at http://www.who.int/foodsafety/publications/micro/en/ march1995.pdf (accessed on July 2011). 
FAO/WHO (1997) 'Risk management and food safety', report of a joint FAO/WHO consultation, Rome, Italy, 27-31 January, Food and Agriculture Organisation, Rome. available at ftp://ftp.fao.org/docrep/fao/w4982e/w4982e00.pdf (accessed on July 2011).

FDA (US Food and Drugs Administration) (2009-last update) CARVER + shock. Obtained through the internet: http://www.fda.gov/Food/FoodDefense/CARVER/default.htm\#whatis.

Gosselin, R.E. Smith, R.P. and Hodge, H.C. (1984) Clinical Toxicology of Commercial Products, 5th ed., Williams \& Wilkins, USA.

Havelaar, A.H., Brul, S., de Jong, A., de Jonge, R., Zwietering, M.H. and Ter Kuile, B.H. (2009) 'Future challenges to microbial food safety', International Journal Food Microbiology, Vol. 139, No. 1, pp.79-94.

International Food Information Council (IFIC) (2006) Foundation Media Guide on Food Safety and Nutrition Food Safety \& Defense, IFIC Foundation Publications Store Customer Service.

Jackson, B.A. and Frelinger, D.R. (2009) Emerging Threats and Security Planning: How Should We Decide What Hypothetical Threats to Worry About?, RAND, Washington, DC.

Khan, A.S., Swerdlow, D.L. and Juranek, D.D. (2001) 'Precautions against biological and chemical terrorism directed at food and water supplies', Public Health Reports, Vol. 116, No. 1, pp.3-14.

Kleter, G.A. and Marvin, H.J. (2009) 'Indicators of emerging hazards and risks to food safety', Food and Chemical and Toxicology, Vol. 47, No. 5, pp.1022-1039.

Manning, L. and Baines, R.N. (2004) 'Effective management of food safety and quality', British Food Journal, Vol. 106, No. 8, pp.598-606.

Quested, T.E., Cook, P.E., Gorris, L.G.M. and Cole, M.B. (2010) 'Trends in technology, trade and consumption likely to impact on microbial food safety', International Journal of Food Microbiology, Epub 10 February 2010, available at doi:10.1016/j.ijfoodmicro.2010.01.043 (accessed on November 2010).

Rasco, B.A. and Bledsoe, G.E. (2005) Bioterrorism and Food Safety, CRC Press, New York.

Sanders, T. (1999) 'Food production and food safety', British Medical Journal, Vol. 318, No. 7199, pp.1689-1693.

SecuFood project website at http://www.secufood.unicampus.it/ (accessed on July 2011).

Setola, R. and De Maggio, M.C. (2009) 'Security of the food supply chain', 31st Annual International Conference of the IEEE EMBS, 2-6 September, Minneapolis, Minnesota, USA.

Shea, D.A. and Gottron, F. (2004) 'Small-scale terrorist attacks using chemical and biological agents: an assessment framework and preliminary comparisons', Technical Report, Federation of American Scientists.

Svensson, G. (2004) 'Key areas, causes and contingency planning in supply chains', International Journal of Physical Distribution \& Logistics Management, Vol. 34, No. 5, pp.414-433.

Warner F. (Ed.) (1986) 'Risk assessment: a study group Amsterdam', Report, Royal Society, London.

WHO (2008) World Health Organization - Department of Food Safety, Terrorist Threats in Food, World Health Organization, Geneva.

Zsidisin, G.A. and Ritchie, B. (2008) Supply Chain Risk, Springer, New York. 